\title{
Investigation of the structure of cement stone, obtaining and optimization of high-strength concrete on mechanically activated binder
}

\author{
Liubov Ksonshkevych ${ }^{1}$, Olena Krantovska ${ }^{1}$, Mykola Petrov ${ }^{1}$, Sergii Synii ${ }^{2,}$, and Anna Uhl $^{3}$ \\ ${ }^{1}$ Odesa State Academy of Civil Engineering and Architecture, Didrihsona st. 4, 65029 Odesa, \\ Ukraine \\ ${ }^{2}$ Lutsk National Technical University, Lvivska st. 75, 43018 Lutsk, Ukraine \\ ${ }^{3}$ Lesya Ukrainka Eastern European National University, Volya Avenue 13, 43025 Lutsk, Ukraine
}

\begin{abstract}
Annotation. Physico-chemical methods of the study of hydrated cement by mechanically activated binding substance with organo-mineral additive (microsilica + C-3) were presented. It was explored the influence of the additive into the kinetics of formation lowly-basic calcium hydrosilicate. The experiment conducted in accordance with a three-factorial D-optimum plan enabled to establish an influence of blending and technological factors $\left(\mathrm{x}_{1}-\right.$ content of microsilica in the binder $-5 \pm 5 \%$; $\mathrm{x}_{2}$ - binder consumption in concrete $-450 \pm 100 \mathrm{~kg} / \mathrm{m}^{3} ; \mathrm{x}_{3}-$ specific area $\left(\mathrm{S}_{\mathrm{sp}}\right)$ of Portland cement $400 \pm 100 \mathrm{~m}^{2} / \mathrm{kg}$ ) on physical and mechanical properties of concrete (compression strength, water absorption). It was established that the use of the mechanically activated blended Portland cement of general purpose with an organomineral additive (microsilica $+\mathrm{C}-3$ ) makes it possible to obtain high-strength concretes which compression strength on the $28^{\text {th }}$ day reaches $120 \mathrm{MPa}$. Optimization of concrete mixes was achieved on the basis of obtained mathematical models that reflect the influence of blending and technological factors on physical and mechanical properties of a high-strength concrete.
\end{abstract}

\section{Introduction}

The amplification of the quality of concrete, more intensive growth of strength, can be achieved through the purposeful change of the structure of the cement stone, as by activating the cement grains[1-3], fillers [4] and microsilica under conditions of intense hydrodynamic influence on them, and due to the modification of their surface area by surfactants $[5,6]$.

Works by Y.M. Bozhenov [7], R. F. Runova [8] et al. found that the use of active mineral additives provides a real opportunity to obtain concrete with preset physicomechanical characteristics, with significant savings Portland cement.

*Corresponding author: sergii.synii@gmail.com 


\section{The purpose of the research}

The purpose of the researches was performing X-ray phase analysis and a study of microstructure of hydrated cement, the bonding substance of which was exposed to mechanical activation in specially made triboactivation, as well as increasing the efficiency of the use of ordinary Portland cement in high-strength concrete due to its mechanical activation and modification by organo-mineral additive.

\section{Research methods}

The research was conducted using of complex of modern methods of physico-chemical analysis with a goal of studying the processes of formation of a phase composition and a microstructure of mechanically activated hydrated cement with the additive of $10 \%$ microsilica $[9,10]$.

X-ray phase research was conducted by the powder method using the diffractometer DRONE-2.0 with SiK $\alpha$ radiation. Experimental samples are pounded in the agathic mortar until complete passing through the sieve No. 008. The prepared sample was moved on the quartz cuvette with proportional layer, previously greased with Vaseline. The cuvette was installed on the goniometric equipment GUR-5. The diffractograms were recorded in the interval of angles $2 \theta=8-50^{\circ}$ by means of detector X-radiation, namely, the scintillation counter with a speed of counting $500 \mathrm{moment} / \mathrm{s}$.

The research of microstructure of prepared samples and photographing the chips of hydrated cement, hydrated by different conditions, were conducted on bit-mapped electron microscope TESLA BS-300 providing possibility of a direct investigation of the surface of solid objects. The bit-mapped electron microscope operates with accelerating tensions to $30 \mathrm{~kW}$. At the same time, the permission $20 \mathrm{~nm}$ is achieved. The electron-optical increase is 5-50000 times.

\section{Result and discussion}

The analysis of diffractograms of hydrated cement in 28 days of maturing is evidence of formation the main characteristic phases of hydrates. During the process of mechanical activation, the processes of hydration are considerably intensified that is confirmed by lowering of density of lines of non-hydrated cement $(d / n=0.26 ; 0.260 ; 0.217 \mathrm{~nm})$, and also by increasing of the density of lines of calcium hydroxide $(d / n=0.26 ; 0.49 \mathrm{~nm})$.

Adding microsilica is accompanied by some regular lowering of density of the lines of the main clinker minerals and by lowering of density of the lines $\mathrm{CaOH}_{2}(d / n=0.49$; $0.261 \mathrm{~nm})$. It is explained by active pozzolanic reaction between Portland cement and microsilica (Fig. 1). The effectiveness of using the mechanical activation in the complex with additive of microsilica is also proved by the microprobe analysis.

There is a part of compactly packed hexagonal aprons which are related to calcium hydroxide and which are observed on photomicrographies (Fig. 2a).

The photomicrography also shows a grain of microsilica which has not come reacted with $\mathrm{Ca}(\mathrm{OH})_{2}$ (Fig. 2a, b).

At the same time, a major part of added microsilica reacts with $\mathrm{Ca}(\mathrm{OH})_{2}$ producing a considerable quantity of calcium hydrosilicate crystals.

Lowly fundamental C-S-H is crystallized in the shape of needles, contributing to the formation of solid connections between the products of hydration of cement, increasing the density and mechanical durability of stone (Fig. 3b). 


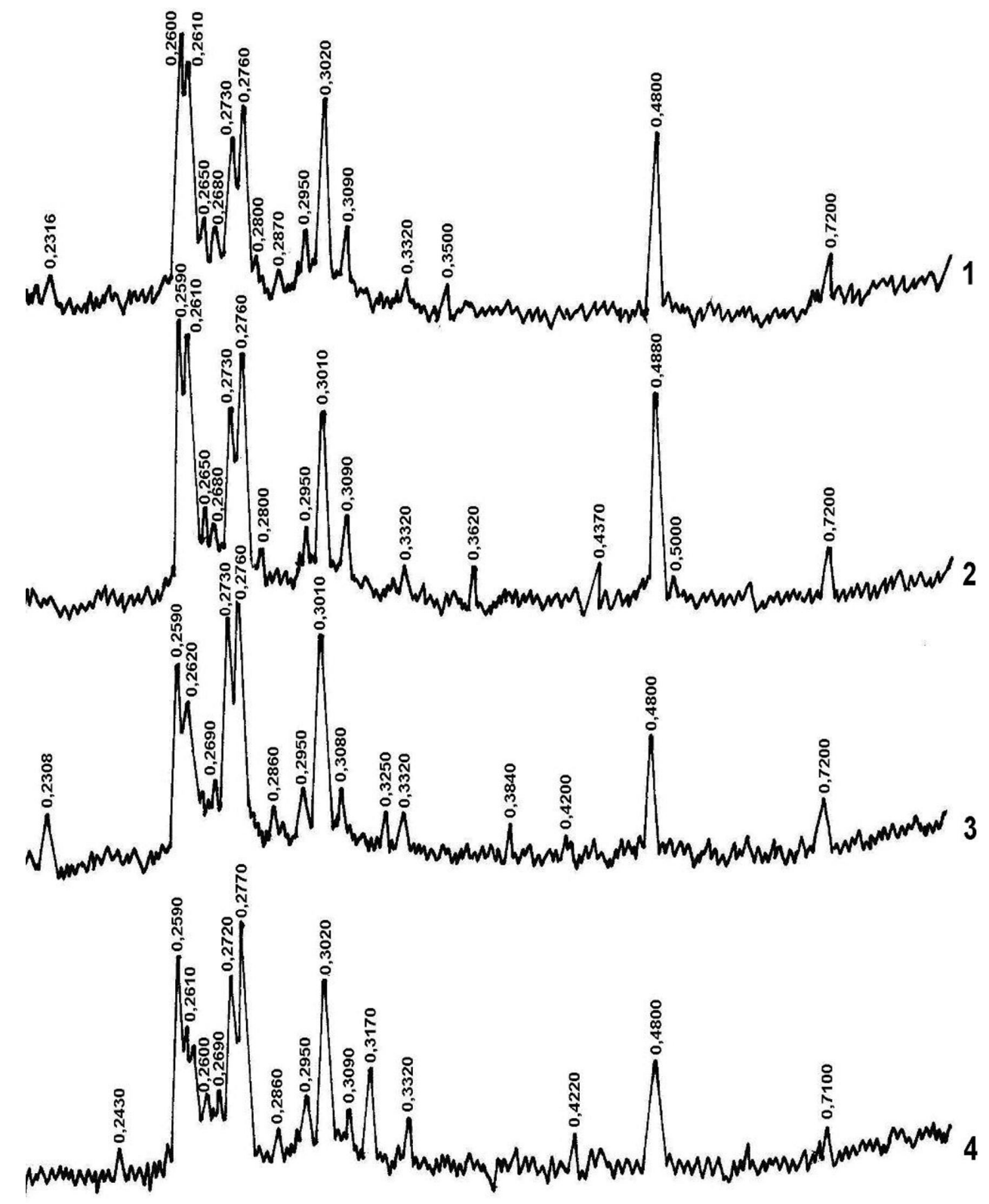

Fig. 1. The diffractograms of Portland cement stone on basis of: 1 - Portland cement without additives; 2 - mechanically activated Portland cement without additives; 3 - Portland cement with $10 \%$ weight of microsilica; 4 - mechanically activated Portland cement with $10 \%$ weight of microsilica.

It was found that adding of organo-mineral additive to Portland cement with simultaneous mechanical activation of bonding substance allows regulating the processes of structure formation. The analysis of the diffractograms of hydrated cement shows that during the process of a mechanical activation the processes of hydration are considerably intensified, and adding $10 \%$ microsilica results in active pozzolanic reaction between Portland cement and microsilica. 


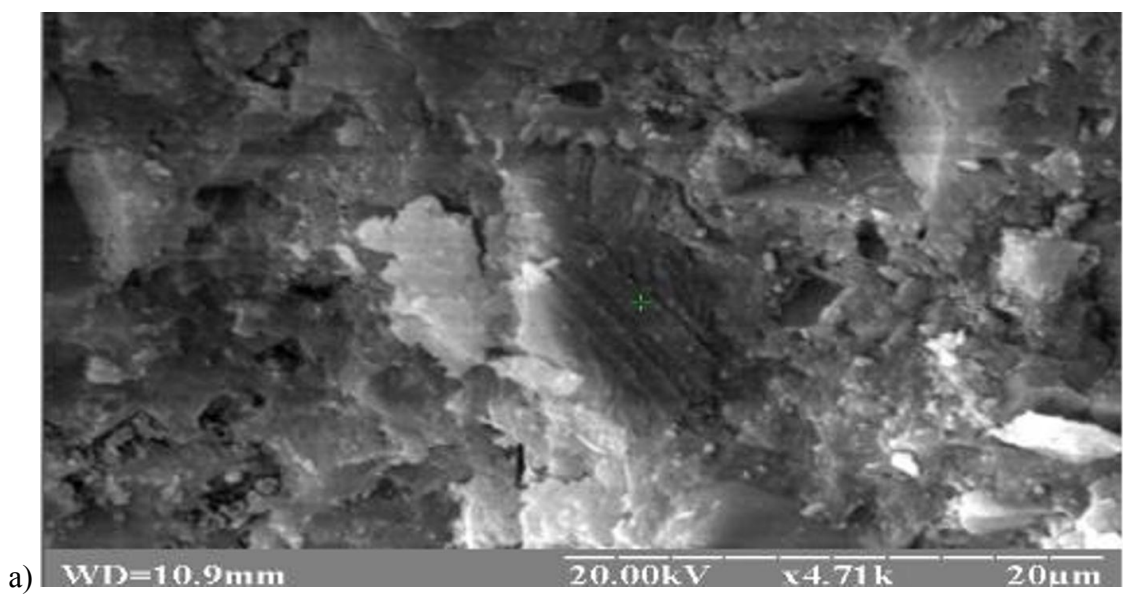

a)

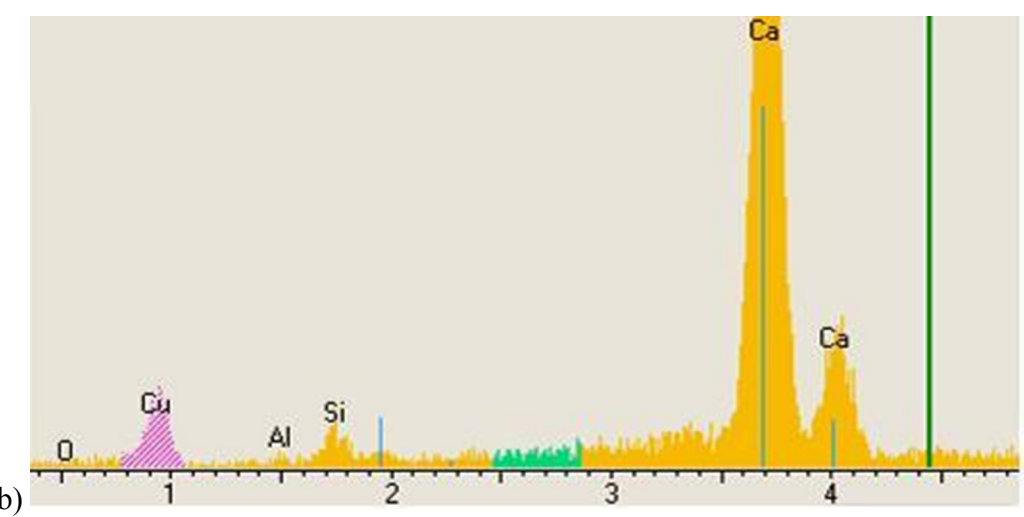

Fig. 2. The microstructure (a) and the spectrum of characteristic X-radiation (b) from a surface of hydrated cement on basis of mechanically activated Portland cement with additive $10 \%$ weight of microsilica.

The studies have shown that the mechanical activation of Portland cement with additive of microsilica changes a qualitative and quantitative composition of new formations that leads to change of conditions of the organization of structure of hydrated cement. For its turn, the change of a character of structure formation excites the change of attributes of solidifying compositions in comparison with cement compositions, received by usual technology [1-3].

It was found that the adding microsilica to Portland cement leads to increasing of durability of hydrated cement in comparison with a control from $26 \%$ to $40 \%$ (according to terms of maturing), Table 1.

The mechanical activation accelerates a role of microsilica in binding substance. In 28 days' age the durability of hydrated cement by mechanically activated bonding substance with additive of $10 \%$ of microsilica is higher in 1.4 in comparison with a control [11]. So that, it may be affirmed that directional structural modification leads to increasing of durability of consolidated cement compositions.

The paper examines the problems associated with production of high-strength concretes by using a general purpose blended Portland cement which is to be mechanically activated and modified with an organomineral additive, and with optimization of concrete mixes taking into account cost-effective use of resources. The research and application of highstrength concrete is an urgent task, especially in road construction [4, 12-13]. 
a)
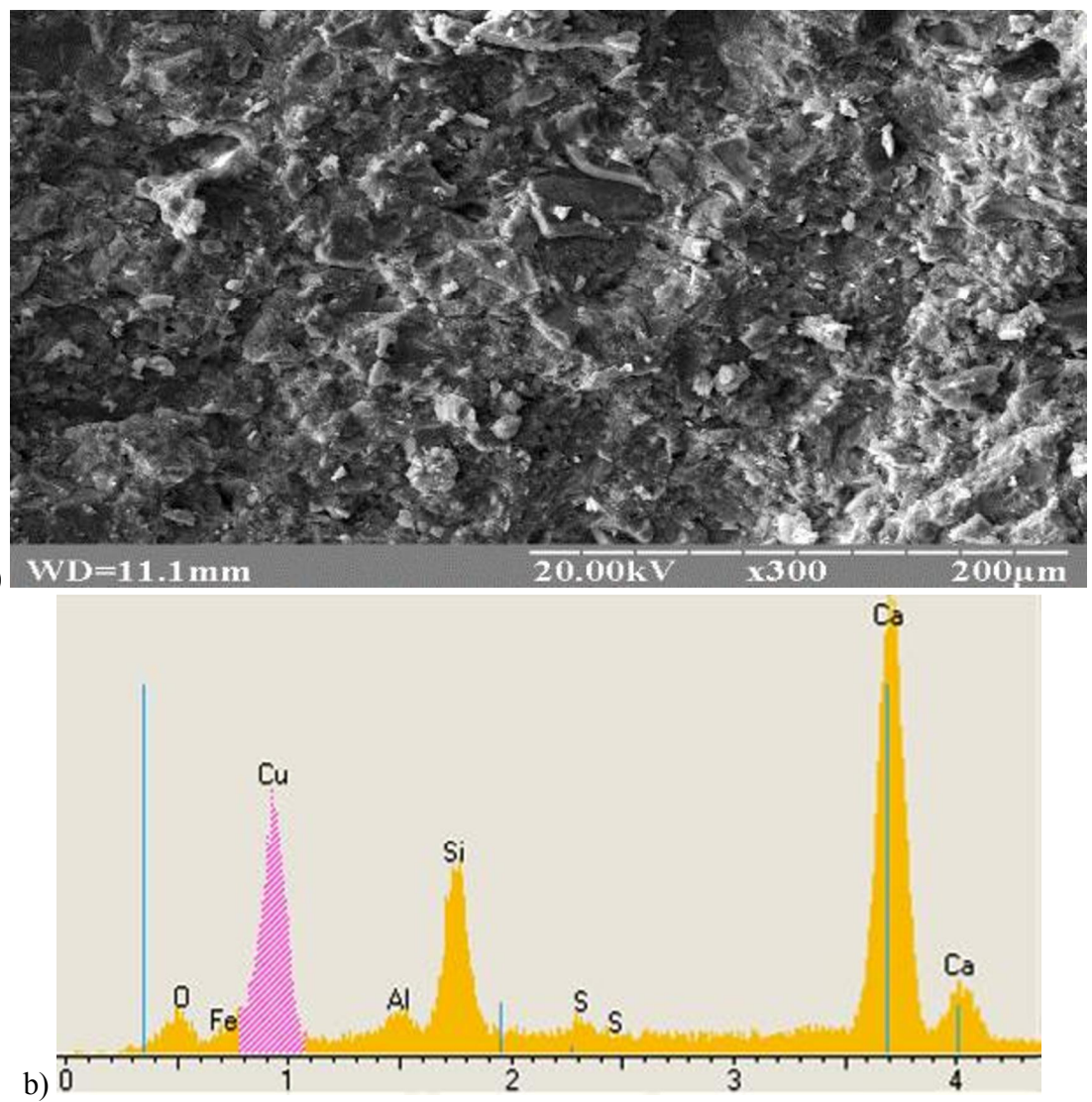

Fig. 3. The microstructure (a) and the spectrum of characteristic X-radiation (b) from the surface of hydrated cement on basis of mechanically activated Portland cement with additive $10 \%$ weight of microsilica.

Table 1. The influence of additive MS on the durability of hydrated cement.

\begin{tabular}{|c|c|c|c|c|c|c|c|c|}
\hline \multirow{3}{*}{$\mathcal{N}$} & \multicolumn{2}{|c|}{$\begin{array}{l}\text { The composition of } \\
\text { bonding substance, } \% \text {, }\end{array}$} & \multicolumn{6}{|c|}{ The durability of hydrated cement $\mathrm{MPa}$, at the age } \\
\hline & \multirow{2}{*}{$\begin{array}{c}\text { Portland- } \\
\text { cement (PC) }\end{array}$} & \multirow{2}{*}{$\begin{array}{c}\text { Micro-silica } \\
\text { (MS) }\end{array}$} & \multicolumn{2}{|c|}{3 days } & \multicolumn{2}{|c|}{7 days } & \multicolumn{2}{|c|}{28 days } \\
\hline & & & $\mathrm{f}_{\text {of curve }}$ & $\mathrm{f}_{\text {of pressure }}$ & $\mathrm{f}_{\text {of curve }}$ & $f_{\text {of pressure }}$ & $\mathrm{f}_{\text {of curve }}$ & $f_{\text {of pressure }}$ \\
\hline \multirow{2}{*}{1} & \multirow{2}{*}{100} & \multirow{2}{*}{0} & 5.08 & 17.1 & 6.7 & 25.2 & 10.9 & 50.8 \\
\hline & & & 4.1 & 12.2 & 5.3 & 18.4 & 8.1 & 36.8 \\
\hline \multirow{2}{*}{2} & \multirow{2}{*}{95} & \multirow{2}{*}{5} & $\underline{6.1}$ & $\underline{21.2}$ & $\underline{8.0}$ & $\underline{28.8}$ & $\underline{11.6}$ & $\underline{64.4}$ \\
\hline & & & $\overline{4.7}$ & $\overline{16.6}$ & $\overline{6.0}$ & $\overline{21.5}$ & $\overline{8.51}$ & $\overline{46.8}$ \\
\hline \multirow{2}{*}{3} & \multirow{2}{*}{90} & \multirow{2}{*}{10} & 7.02 & 23.4 & $\underline{10.8}$ & 34 & $\underline{14}$ & 85.7 \\
\hline & & & $\overline{5.4}$ & $\overline{18.2}$ & $\overline{7.8}$ & $\overline{26}$ & $\overline{10.1}$ & $\overline{61.3}$ \\
\hline
\end{tabular}

Notice: there are significances of durability of hydrated cement by mechanically activated bonding substance above the line; also there is a significance of durability of control samples under the line.

Plan of the experiment and concrete compressive strength value (in the 28 days' age) are summarized in Table 2.

The experiment conducted in accordance with a three-factorial D-optimum plan enabled to establish an influence of blending and technological factors $\left(x_{1}-\right.$ content of microsilica in the binder $-5 \pm 5 \% ; x_{2}$ - binder consumption in concrete $-450 \pm 100 \mathrm{~kg} / \mathrm{m}^{3} ; x_{3}$ - specific 
area $\left(S_{s p}\right)$ of Portland cement $\left.-400 \pm 100 \mathrm{~m}^{2} / \mathrm{kg}\right)$ on physical and mechanical properties of concrete (compression strength, water absorption).

Table 2. Plan of the experiment and mechanical properties of concrete.

\begin{tabular}{|c|c|c|c|c|c|c|c|c|c|c|}
\hline \multirow[b]{2}{*}{ № } & \multicolumn{3}{|c|}{$\begin{array}{c}\text { Variation } \\
\text { levels }\end{array}$} & \multirow{2}{*}{ 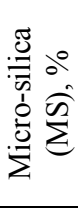 } & \multirow{2}{*}{ 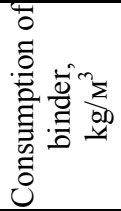 } & \multirow{2}{*}{ 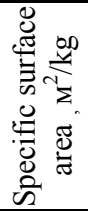 } & \multicolumn{4}{|c|}{ Responses } \\
\hline & $x_{1}$ & $x_{2}$ & $x_{3}$ & & & & $\begin{array}{l}\mathrm{f}_{\text {cube }}^{\mathrm{K}} \\
\mathrm{MPa}\end{array}$ & $\begin{array}{l}\mathrm{f}_{\text {cube, } \mathrm{w}}^{\mathrm{K}}, \\
\mathrm{MPa}\end{array}$ & $\begin{array}{l}\mathrm{f}_{\text {cube }}^{\mathrm{a}} \\
\mathrm{MPa}\end{array}$ & $\begin{array}{l}\mathrm{f}_{\text {cube,w }}^{\mathrm{a}}, \\
\mathrm{MPa}\end{array}$ \\
\hline 1 & - & - & - & 0 & 350 & 300 & 43.6 & 41.8 & 59.7 & 56.4 \\
\hline 2 & + & - & - & 10 & 350 & 300 & 52.3 & 43.3 & 73.2 & 60.6 \\
\hline 3 & - & + & - & 0 & 550 & 300 & 53.9 & 49.5 & 75.5 & 64.4 \\
\hline 4 & + & + & - & 10 & 550 & 300 & 69.5 & 61.4 & 97.3 & 85.9 \\
\hline 5 & - & - & + & 0 & 350 & 500 & 52.7 & 44.8 & 68.5 & 58.2 \\
\hline 6 & + & - & + & 10 & 350 & 500 & 64.3 & 51.3 & 90 & 71.8 \\
\hline 7 & - & + & + & 0 & 550 & 500 & 72.8 & 69.3 & 98.3 & 90.1 \\
\hline 8 & + & + & + & 10 & 550 & 500 & 88.4 & 71.3 & 123.8 & 99.8 \\
\hline 9 & - & 0 & 0 & 0 & 450 & 400 & 64.9 & 55.9 & 84.4 & 72.7 \\
\hline 10 & + & 0 & 0 & 10 & 450 & 400 & 81.4 & 67.5 & 105.8 & 94.5 \\
\hline 1 & 2 & 3 & 4 & 5 & 6 & 7 & 8 & 9 & 10 & 11 \\
\hline 11 & 0 & - & 0 & 5 & 350 & 400 & 61.6 & 57.6 & 83.2 & 77.8 \\
\hline 12 & 0 & + & 0 & 5 & 550 & 400 & 75.2 & 66.1 & 101 & 89.2 \\
\hline 13 & 0 & 0 & - & 5 & 450 & 300 & 53.9 & 50.4 & 72.8 & 68.0 \\
\hline 14 & 0 & 0 & + & 5 & 450 & 500 & 58.1 & 50.5 & 78.4 & 68.2 \\
\hline 15 & 0 & 0 & 0 & 5 & 450 & 400 & 73.4 & 63.5 & 99.1 & 89.8 \\
\hline
\end{tabular}

The choice of several variants of optimal compositions of high-strength concrete was carried out graphically by diagrams constructed according to the corresponding ES-models.

Isolines were placed on the cube displaying the levels of basic physico-mechanical properties of mechanically activated concrete at the 28 days' age, and areas not meeting the limitation criteria were excluded (Fig. 4).

As a common limitation criterion for all three alternatives, the concrete softening coefficient not less than $0.85\left(K_{s} \geq 0.85\right)$ was adopted. The compression strength of concrete - 80, 90 and $100 \mathrm{MPa}$ was assumed as the second limitation criterion.

Further, optimal compositions were chosen taking into account the required criteria water absorption and the specific surface area of the binding agent.

A is the consumption of binder $550 \mathrm{~kg} / \mathrm{m}^{3}$, relatively low specific surface area binder (about $320 \mathrm{~m}^{2} / \mathrm{kg}$ ) and using $10 \%$ microsilica. This composition can be recommended for the basis energy saving to the grinding of the binding agent.

$B$ is the consumption of binder of $550 \mathrm{~kg} / \mathrm{m}^{3}$, the average specific surface area of the binding material (about $400 \mathrm{~m}^{2} / \mathrm{kg}$ ) and without the microsilica. This composition can be recommended for a reason the absence of the need for an additional technological operation - the introduction of microsilica.

In addition, the composition of B shows less water absorption compared to composition A, which suggests its greater potentially durability. 
$\mathrm{C}$ is the consumption of binder of $450 \mathrm{~kg} / \mathrm{m}^{3}$, a specific binding surface area of about $380 \mathrm{~m}^{2} / \mathrm{kg}$ and in the absence of microsilica. This composition can be recommended for reducing the consumption of binder.

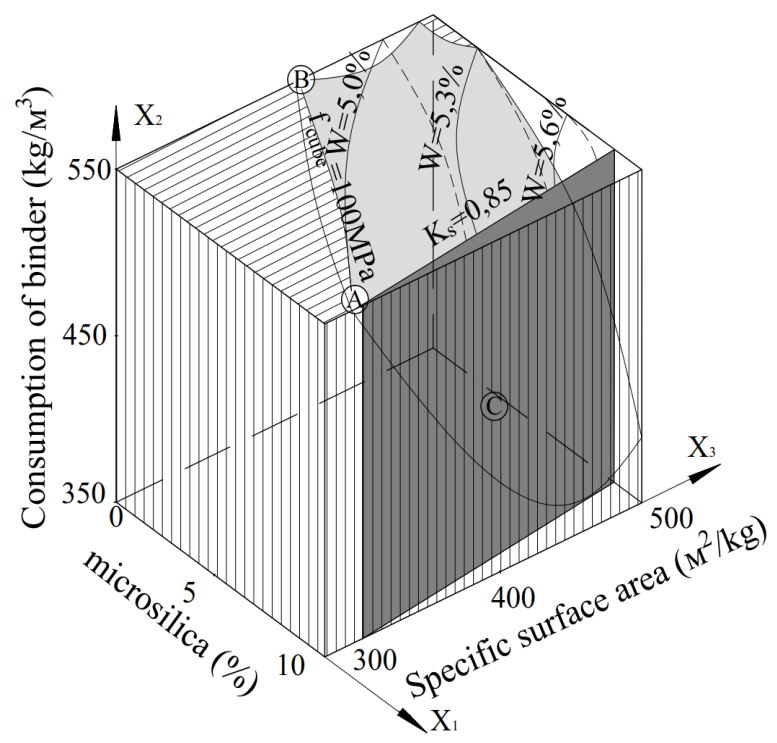

Fig. 4. Selection of optimal composition of concrete in a 3-dimensional diagram.

Solution of the optimization problem enabled to select the optimum compositions of high-strength concretes that can be used in dependence from needed levels for a particular task with due account of the economic efficiency and current prices of energy, equipment and raw materials.

\section{Conclusions}

The inclusion of microsilica in a composition of binding substance contributes to the formation of strong connections between the products of hydration of cement that is confirmed by the facts on a formation of lowly-basic calcium hydrosilicates.

The mechanical activation of grains of cement and microsilica assures the increase of mechanical characteristic of cement stone in diapason from 26 to $40 \%$.

It was established experimentally that mechanical activation of blended Portland cement of a general purpose with adding microsilica and C-3 superplasticizer allows to obtain heavy concretes of $\mathrm{C} 35 / 45 \ldots \mathrm{C} 90 / 105$ classes with consumption of binder from 450 to $550 \mathrm{~kg} / \mathrm{m}^{3}$. The results of the research made it possible to optimize compositions of C70/85...C $90 / 105$ high-strength concrete.

\section{References}

1. I.V. Barabash, Mechanochemical Activation of Mineral Weavers, Training Manual, (Odessa, Astroprint, 2002)

2. S.I. Fedorkin. Mechanoactivation of secondary raw materials in the production of building materials (Simferopol, Tavria, 1997)

3. L. Ksonshkevych. High-strength concrete on the mechanically activated binder: dis. Cand. tech Sciences: 05.23.05. (Odessa, 2013) 
4. O. Andriichuk, V. Babich, I. Yasyuk, S. Uzhehov, MATEC Web of Conferences, 116, 02001 (2017)

5. V. Ramakrishnan, W. Coyle, S. Pande, Indian Concrete J., 54:1, 23-26 (1980)

6. Constitutive modeling o / high strength/ high performance concrete, FIB Bulletin 42, Sprint-Digital-Druck (Stuttgart, 2008)

7. Y.M. Bazhenov, Concrete technology (Moscow, Publishing house ABC, 2003)

8. R.F. Runova, I.I . Rudenko, V.V. Troyan, V.V. Tovstonis, S.P. Shcherbyna, L.D. Pashina, Building materials, products and sanitary equipment, 29, 91-97 (2008)

9. S.S. Gorelik, L.N. Rastorguev, J.A. Skakov. Radiographical and electro-optical analysis. Tutorials for students. -3 rd ed. comp. alt. (M., MISSIS, 1994)

10. V.M. Melnyk, A.V. Shostak, Quantitative stereomicrofractography: Monograph (Lutsk, PVD Tverdinya, 2010)

11. L. Ksonshkevych, I. Barabash, Herald OSACI, Odessa, 40, 161-167 (2010)

12. O.V. Andriichuk, E.M. Babych, Materials Science, New York, 52:4, 509-513 (2017)

13. O. Mikulich, V. Shvabyuk, I. Pasternak, O. Andriichuk, Mechanics Research Communications, 91, 107-111 (2018) 